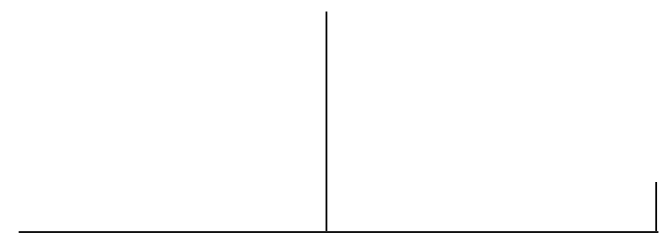

Rev. Latinoam. Psicopat. Fund., São Paulo, v. 12, n. 2, p. 303-315, junho 2009

\title{
Sexuação e formas contemporâneas de representação*
}

Maria Cristina Poli

\begin{abstract}
$O$ artigo se propõe a trabalhar o ponto de enlace entre $o$ singular do sujeito sexuado e os modos de representação, culturais por princípio. Acompanhamos os passos de Foucault que, através do debate com Magritte, contextualiza as vicissitudes da representação nos permitindo abordar, desde a perspectiva da psicanálise, sua relação com a sexuação. Filosofia, arte e psicanálise são práxis distintas, porém estão mergulhadas no mesmo caldo cultural, precisando ter seus debates atualizados.
\end{abstract}

Palavras-chave: Corpo, arte, psicanálise, Lacan, Freud, Foucault

* Esse artigo é resultante do trabalho de pesquisa "O campo da linguagem na fala e na escrita como fundamento do discurso e da experiência psicanalítica", financiado pelo Ministério da Ciência e Tecnologia/Conselho Nacional de Desenvolvimento Científico e Tecnológico - MCT/CNPq. 


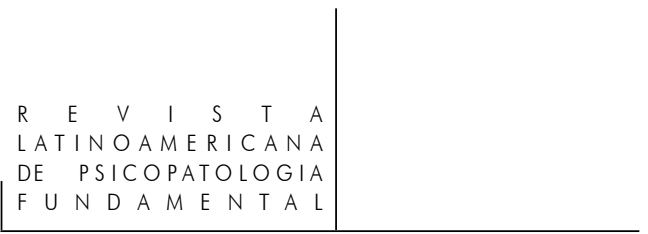

O mundo gosta de denegrir o brilhante e arrastar na lama o sublime.

(Schiller, 1801, apud Freud, 1910)

\section{Fetichismo: o corpo como obra de arte}

No texto que escreveu sobre Leonardo da Vinci, Freud (1910) faz algumas de suas mais audaciosas interpretações do enlace entre criação artística e disposição pulsional. Encontramos nesse texto o elo, muitas vezes perdido, entre dois importantes operadores no diálogo da psicanálise com a arte e com a cultura: a sublimação e o fetichismo. Eles colocam em causa, também, o laço entre representação e corpo sexuado, de um modo que precisa ser explicitado. Podemos iniciar sua abordagem pela origem do termo "fetiche" - representante dos deuses e elemento de culto sagrado - que indica o apoio das representações religiosas na atividade sexual:

Os dados trabalhosamente reunidos pelos investigadores da civilização nos proporcionam a certeza de que os genitais constituíram primitivamente o orgulho e a esperança dos homens; foram objeto de um culto divino e transferiram sua divindade a todas as novas atividades humanas. De sua essência surgiram, por sublimação, inúmeros deuses, e quando a conexão das religiões oficiais com a atividade sexual ficou oculta à consciência geral, existiram cultos secretos, que se esforçaram em mantê-la viva entre um escasso número de iniciados. Por último, se extraiu tanto o elemento divino e santo da sexualidade, que o esgotado remanescente se tornou objeto de desprezo. (p. 1597)

É nesse texto sobre Leonardo da Vinci que Freud se propõe a ler a obra do artista como uma formação do inconsciente, como um sonho. O sorriso de Gioconda, por exemplo, assim como os detalhes do quadro da Virgem com o menino Jesus e Santa Ana são interpretados como expressões de complexos inconscientes. As figuras retratadas, escreve Freud, "se acham confundidas como imagens oníricas mal 
condensadas" (p. 1607). São as ambivalências, as fixações eróticas, os desejos desconhecidos e sublimados que o psicanalista encontra ali, no cotejamento da biografia do autor com sua produção. No caso de Leonardo, Freud propõe que a sublimação dos desejos eróticos primários permitiu a expressão da pulsão investigativa da criança - acrescida pela forte ligação erótica com a mãe - sem deparar-se com as barreiras do recalque e da inibição, guardando, portanto, especial intensidade.

Leonardo - propõe Freud - era homossexual, havendo, no entanto, substituído a tendência erótica pela produção artística e científica. Note-se bem: ele não tinha uma prática homoerótica; porém, Freud afirma que sua posição e sua produção era a de um homossexual. Sua obra tinha valor de fetiche: tal como o "cortador de tranças", o artista fazia e desfazia a castração da mãe.

Podemos hoje considerar excessivo o afã interpretativo de Freud. Ele comporta, no entanto, algumas importantes lições que precisaríamos lembrar quando nos dedicamos a trabalhar na interface psicanálise e cultura - entendendo por cultura os diferentes discursos e práticas que compõem um certo contexto histórico-social. Primeiro, a possibilidade de produzir uma leitura que não imponha um crivo psicopatológico e valorativo. Freud expressa, de uma forma absolutamente clara e exemplar, sua admiração a Leonardo da Vinci. Ao mesmo tempo, observa a manutenção de uma posição erótica infantil e de fixações pulsionais incestuosas sem que isso em nada diminua ou provoque alguma objeção ao valor do artista e de sua obra. Pelo contrário, no lugar do diagnóstico preconceituoso, Freud vale-se do "caso Leonardo" para questionar os critérios de normalidade. Além disso - e como um segundo aspecto a ser conservado como um grande ensinamento da posição de leitura cultural de Freud - a manutenção e sustentação de uma posição crítica a certos determinantes culturais. Justamente aqueles que tendem a moralizar os modos singulares de expressão da sexualidade.

É, pois, com base nessa herança que Freud nos legou, e tentando fazer jus a ela, que vamos avançar no tema proposto: o enlace entre sexuação e formas contemporâneas de representação. Henri Jeudy (2002), no livro $O$ corpo como objeto de arte, coloca a questão sobre o estatuto do corpo na contemporaneidade a partir de sua expressão cultural, nas artes. Ele parte de uma observação interessante, a multiplicação de estátuas humanas nas ruas das grandes cidades. $\mathrm{O}$ corpo feito estátua, paralisado e mortificado, serve de paradigma para a leitura de seu estatuto nas obras de arte. Efetivamente, o corpo na obra é, desde já, morto, congelado, petrificado e, assim, protegido dos efeitos do tempo. Como não lembrar de $O$ retrato de Dorian Gray (Wilde, 1998), espécie de duplo que envelhece no lugar do modelo, apenas esperando o momento de cobrar seu devido lugar na eternidade à custa, justamente, daquele que lhe serviu de referente. 


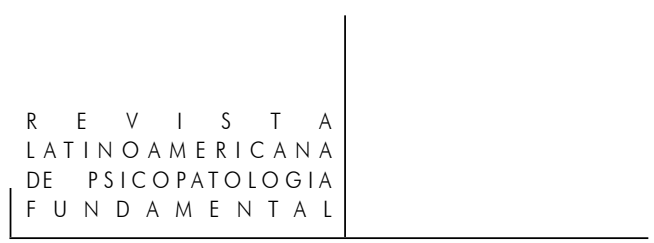

Interessa-nos pensar esse efeito de retorno que a "estetização da vida cotidiana" produz. Jeudy nos lembra o quanto tal cenário esteticizado participa das montagens sádicas e masoquistas. Não se pode desconhecer o valor erótico da mortificação, da objetalização e reificação do corpo. Assim, se ao virar objeto de arte ele é dessexualizado, sublimado, por outro lado, a estetização é condição da erótica: é o pequeno pedaço fixado como objeto, sacrificado e sacralizado, que se produz como fetiche.

No texto sobre o fetichismo (1927), encontramos um apoio interessante a esse respeito. Escreve o autor:

Em casos muito estilizados, o próprio fetiche aloja em sua estrutura tanto o repúdio como a afirmação da castração. Assim ocorreu com um homem que tinha por fetiche um suspensório, destes que também podem ser usado como calção de banho. Essa peça cobria inteiramente os órgãos genitais e ocultava assim a distinção entre eles. A análise mostrou que isso significava que as mulheres eram castradas e que não eram castradas e permitia ainda a hipótese de que também os homens eram castrados, porque todas essas possibilidades podiam ser igualmente bem ocultas sob o suspensório - cujo primeiro precursor infantil havia sido a folha de parreira de uma estátua. (p. 2996)

Calção de banho, folha de parreira - o kitsch da representação, corriqueira no universo pornô, denota aqui seu valor de objeto-fetiche na sustentação da erótica. Para Jeudy (2002), essas imagens clichês, que perfazem grande parte da produção estética contemporânea, são resultantes da "vontade manifesta [da arte no século 20] de romper com a tirania do espelho" (p.175). É nesse contexto, justamente, que a produção estética, avalia Jeudy, se faz plena de estereótipos culturais. A crítica ao referente especular impõe o clichê. Estamos no cerne disso que Freud denominou de fetiche e seu efeito trompe l'oeil: simulação da castração que implica reconhecimento e recusa ao mesmo tempo.

Fetichismo e simulacro, temas bastante presentes na crítica cultural contemporânea. Ao recuperar seu valor erótico na dinâmica pulsional (mais além do sexual, i.e., do referente fálico), a psicanálise poderia posicionar diferentemente a leitura e interpretação dessa produção cultural? A questão não é simples. Jeudy (2002) enuncia um dos aspectos de sua complexidade:

Dos escritos de Leonardo às performances contemporâneas de Orlan, o tratamento estético do corpo humano terá sofrido todas as metamorfoses imagináveis. Mas o que faz supor que as mais comuns e as mais singulares representações do corpo humano tenham alguma relação com a construção artística de tais representações? (...) São as imagens corporais que, na vida, de maneira acidental, provocam as interferências com as representações do corpo na arte. Vamos mais longe ainda: são as imagens corporais que, na nossa própria 
vida, não deixam de restituir às representações artísticas do corpo seu poder visionário e alucinatório. (p. 26-27)

Interessante expressão: "restituir às representações artísticas do corpo seu poder visionário e alucinatório". A arte, enquanto ethos da representação, precisa do corpo real, assim como, poderíamos acrescentar, o fetiche necessita da castração para nela apoiar seu desconhecimento. Qual arte, no entanto? Se pensarmos com Freud (1900), no modelo da produção onírica, é na construção da borda, no entorno do "umbigo do sonho", que tal representação se situa. Lacan recorre a Heidegger na alegoria da construção do vaso que produz o vazio (Lacan, 1988). Imagem eloquente do caráter moebiano do lugar do corpo na representação artística: entre o sexual e o erótico, entre o véu do falo e o recorte do objeto.

Outra questão ainda se impõe: como situar os efeitos de retorno da produção cultural dessa borda no cotidiano das práticas eróticas e afirmações sexuadas? De que modo a produção estética afeta os modos singulares de atividade sexual e de sexuação? Entramos aí no difícil terreno das condições a priorísticas do campo do Outro na produção do sujeito.

Se considerarmos a atualidade dessa questão na clínica e no social, podemos auferir sua complexidade. A produção da imagem do corpo - produção a um só tempo estética e erótica (visto que comporta um gozo) - é um dos principais modos de expressão pelo sujeito de sua posição de alienação. As formações do inconsciente - o sintoma histérico em particular - perfazem uma imagem, literalizam uma escrita. É um corpo que se dá a ver e que se dá a ler, segundo um código que demanda ser decifrado. Além disso, como demonstra Lacan (1985), quando há corpo (en corps, encore), se trata do gozo (jouissance, j'ouis sens).

Estamos aí no litoral, entre sujeito e Outro. Em particular, este que concerne à borda entre o erótico e o sexual, entre o campo da representação (inscrição fálica) e posição sexuada (i.e., os modos singulares de inscrição e legitimação do gozo). Na inscrição de heterogêneos (corpo e linguagem), encontramos o trabalho do "não", construção da borda entre o nem um, nem outro que se traduz na psicanálise pelas condições de afirmação sexuada do sujeito.

\section{As palavras e as imagens}

Para avançar no caminho indicado, faremos um certo desvio de rota chamando para o trabalho um importante diálogo ocorrido entre um filósofo e um artista. 


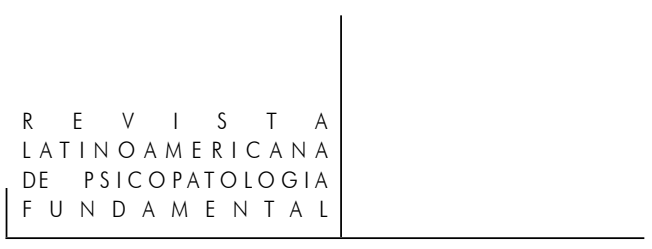

Vamos até 1967, quando Foucault publica um pequeno texto intitulado "As palavras e as imagens" (2005). Alguns anos depois, no inicio dos anos 1970, segue-se um pequeno livro chamado Isto não é um cachimbo (1988). Ambos os escritos tratam de temas derivados de sua grande obra As palavras e as coisas, tocando em pontos que a problematizam a partir da perspectiva da história da arte. Foucault desculpa-se: não é essa sua área de competência. Não obstante, vale-se nos textos mencionados de argumentos extraídos da obra de Magritte, reproduzidos já nos seus títulos.

De fato, o filósofo aceita o desafio que lhe chega através de missivas do artista (Magritte, apud Foucault, 1988), com questões que poderíamos resumir assim: qual a relação entre similitude e semelhança? São a mesma coisa ou coisas diferentes? A pergunta contém a provocação. Magritte leu bem o importante livro de Foucault. Acompanhou seus argumentos sobre os fundamentos de nossa moderna forma de conceber a linguagem. Entre eles, indicava o filósofo, a passagem de um sistema de saber regulado por similitudes, para outro sustentado na ordenação de identidades e diferenças. Mudanças operadas pelo desenraizamento da linguagem e do mundo que implicou, entre outras coisas, a produção de um corte epistemológico entre o que se diz e o que se vê.

É em relação a este ponto que o pintor dirige-se ao filósofo para lhe interrogar se não caberia tratar a similitude como uma propriedade das coisas visíveis, enquanto a semelhança seria um atributo do pensamento. Nesse sentido, "a pintura - escreve Magritte - faz intervir uma dificuldade: há o pensamento que vê e que pode ser descrito visivelmente" (apud Foucault, 1988, p. 82). A pintura dá a ver o pensamento invisível do pintor; alteram-se, assim, os termos da oposição propostos por Foucault. Porém, acrescenta, mantém-se ainda o mistério - um dos nomes do incognoscível - sem confundi-lo com o "invisível". Ele é evocado na ordem do pensamento pela união do visível e do invisível. Junto à carta, Magritte remete algumas reproduções suas, entre as quais a famosa obra Traição das imagens, acrescido da observação: "o título não contradiz o desenho, ele o afirma de outro modo" (p. 83).

Estamos em 1966, ano de lançamento de As palavras e as coisas (Foucault, 1990) e dessa correspondência inusitada entre um pintor e um filósofo. O quadro de Magritte, no entanto, já tem nessa ocasião quarenta anos de sua primeira versão. A imagem do cachimbo acompanhada da frase "Isto não é um cachimbo" ganhará diferentes versões ao longo do tempo. Também com outros objetos, como o de 1964, no qual a imagem é a de uma maça e a frase "Isto não é uma maça". Mantém-se aí a mesma estrutura: uma imagem que se afirma, tendo por base a similitude com um objeto natural, e uma frase escrita no negativo. Conforme explica Magritte (apud Foucault, 1988) na carta a Foucault, a frase apor- 
ta através da negativa o princípio da semelhança (e não da similitude). Ela explicita sua condição, dando a ver o que no único recurso à imagem permaneceria "invisível": a condição do "não" como princípio da afirmação.

A primeira versão desse quadro é contemporânea da publicação por Freud (1925a) do texto "A negação". Neste - lembremos - ele inicia apresentando ao leitor o fragmento de uma análise. O paciente sonha com uma mulher e apressa-se a dizer ao analista: "Você me pergunta quem pode ser essa pessoa no meu sonho. Minha mãe, digo logo, não é". Ao que Freud acrescenta "Trata-se certamente da mãe". O "não" é a marca do recalque. Como se o paciente dissesse: "É realmente minha mãe, mas eu não gostaria de reconhecê-lo" (p. 2884). (A lógica, como se pode perceber, é similar à que está em causa no quadro de Magritte, cf. Poli, 2007).

Efetivamente, no sonho, assim como nas demais formações do inconsciente, está em causa a relação entre o que se vê e o que se diz, inscrevendo o registro singular da realidade psíquica. Porém, aqui - na psicanálise - o "que se vê" situa o campo de reunião impossível entre imagem e olhar (pulsão escópica); "o que se diz", por sua vez, localiza o encontro faltoso entre a função da fala e o campo da linguagem. Entre um e outro - sujeito e Outro -, o desencontro se duplica: "representante da representação", nomeia Freud, reconstituindo o percurso de sua formação, a partir da inscrição dos juízos, pela intervenção originária do "não". Partícula mínima e primária a marcar o corpo como traço de passagem pelo circuito das pulsões.

Em outro texto de Freud (1925b), escrito no mesmo ano, "Algumas consequências psíquicas da diferença anatômica entre os sexos", encontramos a derivação do mesmo tema. Neste texto, o termo "falo" oscila de seu estatuto significante - destacado por Lacan na fantasia da "primazia do falo" e da "inveja fálica" - ao de nome atribuído ao órgão peniano, presente ou ausente conforme a anatomia. Assim, sob a pena de Freud, o falo "é" e "não é" o pênis, do qual derivam as posições sexuadas a partir do Édipo. Afirmar-se mulher ou homem responde à incidência desse segundo "não" - o recalque secundário - que inscreve o sujeito na repartição, própria à lógica fálica.

\section{Sexuação e o trabalho da metáfora}

Foucault retoma seu trabalho, aceitando o convite do artista para refletir sobre o estatuto da representação desde a perspectiva das artes plásticas. Nesse pequeno livro que toma emprestado a frase do quadro de Magritte, ele analisa as relações entre representação plástica e referência linguística na história da arte. 


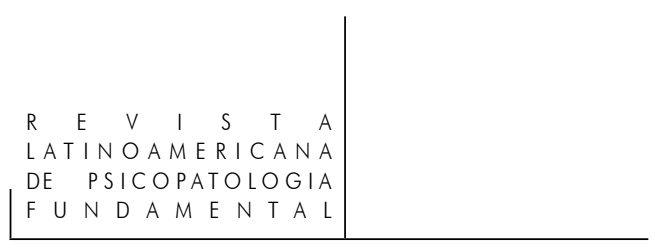

Ele escreve: "Dois princípios reinaram, eu creio, sobre a pintura ocidental, do século quinze até o século vinte. $O$ primeiro afirma a separação entre representação plástica (que implica a semelhança) e a referência linguística (que a exclui). Faz-se ver pela semelhança, fala-se pela diferença" (1988, p.39).

O autor faz notar que tal separação implica, historicamente, uma relação de hierarquia. Desde estabelecida a clivagem, observa-se uma relação de subordinação mútua e alternada entre signo verbal e representação visual.

Um pintor como Paul Klee, nomeia Foucault, rompe em sua obra com um tal princípio. Ao justapor em seus quadros figuras e signos, objetos naturais e pautas musicais, expõe uma "onomatopeia gráfica" (p. 41). Também a obra de Kandinski é evocada pelo filósofo, porém, desta vez, por oposição ao segundo princípio da pintura ocidental moderna: "a equivalência entre o fato da semelhança e a afirmação de um laço representativo" (p. 41). Em seus quadros, Kandinski afirma sem apoiar-se em uma semelhança. O quadro é nomeado a partir do gesto que o constitui, em uma redução minimalista da imagem a traços e cores.

A obra de Magritte se associaria à desses pintores, segundo a leitura de Foucault, ao colocar também em questão tais princípios ordenadores. Contudo, sua contraposição se produz quando leva ao paroxismo a tensão entre elemento gráfico e imagem plástica. A obra é, então, a própria ruptura que impede de sermos, ao mesmo tempo, leitor e espectador. A não relação, assim cifrada, se afirma na escolha do título da obra. Conforme testemunha o próprio Magritte: "Os títulos são escolhidos de tal maneira que impedem de situar meus quadros numa região familiar que o automatismo do pensamento não deixaria de suscitar a fim de se subtrair à inquietação" (apud Foucault, 1988, p. 47).

O título desloca o leitor/espectador a uma posição terceira: nem imagem, nem escrita. O jogo metonímico do espelho, que provoca contradições, desloca-se para o trabalho da metáfora na produção de um lugar de enunciação. O título "A traição das imagens" atestaria a função desse lugar terceiro.

Na teoria psicanalítica, o trabalho da metáfora na assunção de uma posição sexuada remete à incidência do referente fálico. Estamos aí na lógica binária da oposição "ter/não ter" o falo e seus efeitos de sentido na assunção das posições homem/mulher. Lacan (1958-1959/Inédito) o enuncia na clássica proposição "o homem não é sem tê-lo; a mulher é sem tê-lo" - que compõe a comédia dos sexos. Porém, além dessa referência o trabalho da metáfora pode ser considerado nos modos de o sujeito se situar no gozo do objeto (esse que "não" está ali). Nesta referência, tal como Lacan (1985) a concebe no seminário 20, desloca-se o acento da metáfora fálica (a incidência do significante da falta) para a erótica (a colocação em ato do objeto da pulsão, que ele nomeia letra).

As fórmulas da sexuação (Lacan, 1985) são, portanto, para serem lidas como um quadro de Magritte. O lócus da enunciação - ponto de reunião entre 
palavras e imagens, pulsão e significante - situa-se em uma particular dobra do dentro-fora do quadro. Está na nomeação do gesto, como em Kandinski, quando sexuação e exercício sexual se afirmam mutuamente. Ou na produção "onomatopéica" de um corpo "tatuado", "maquiado" por riscos e significantes que curto-circuita os jogos especulares e suas oposições binárias, como em Klee.

O quadro de Magritte A traição das imagens guarda bem a referência a esses dois níveis de leitura da metáfora. O título evoca, como dissemos, a não correspondência entre imagem e escrita. Mas, ao denominá-la "traição", deixa antever a possibilidade de uma relação de "fidelidade" na qual a correspondência entre signo linguístico e imagem visual não fosse rompida. Temos aí um nível de velamento, que toma o título como explicação da obra. Nominação que se situa numa relação de contiguidade com a imagem sem produzir enigma.

Outro nível de metáfora situa o título como ironia ou chiste. Na obra de Magritte, também o título compõe a ironia do engano, quando - como ele mesmo apresenta a questão a Foucault - o que estava em causa na sua composição era o jogo com a semelhança e a similitude, fazendo-as coexistir num mesmo plano. O que se vê ali, portanto, é a presença do autor na obra: conjunção de sujeito e objeto na cena produzida, rompendo as barreiras entre dentro-fora do quadro. O espectador é convocado a, a cada vez, decifrar o enigma, decidindo o ponto desde o qual tomará posição. Nesse sentido, o enigma do quadro produz uma performance. Ele exige de quem o olha, e se deixa interrogar por ele, que produza um julgamento. Um ato, como diz Freud (1925a), que conduz do pensar ao agir.

Não teria efeito semelhante à provocação enunciada no axioma lacaniano "a mulher não existe?" (Lacan, 1985).

\section{Para concluir: a escritura como travestimento}

Acompanhamos até aqui os passos de Foucault que, através da leitura de Magritte, nos permitiu contextualizar algo das vicissitudes da representação e da sexuação desde a perspectiva da psicanálise. Efetivamente, filosofia, arte e psicanálise compartilham nesse ponto um objeto "quase" em comum. Práxis distintas, certamente, porém mergulhadas no mesmo caldo cultural.

A dificuldade maior começa quando, como reconhece Foucault no pequeno texto de 1967 "As palavras e as imagens", se pretende tratar dos "discursos reais". Aí não basta confrontar modelos de leitura e análise. É preciso considerar "o funcionamento recíproco dos sistemas na realidade de uma cultura" (Foucault, 2005, p. 81). Ou, como preferiríamos dizer: o funcionamento recíproco dos sistemas de realidade de uma cultura. 


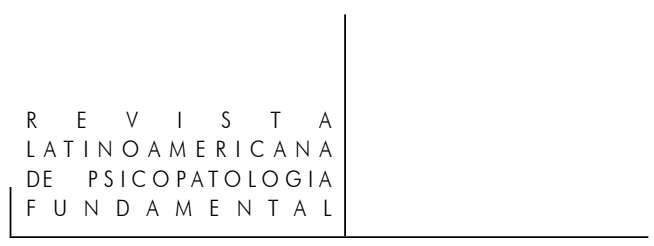

A questão que gostaríamos de deixar indicada é se hoje ainda estaríamos operando, no campo das representações, segundo os princípios ordenadores propostos por Foucault. As modificações operadas, nas últimas décadas, nos modos de apresentação, fruição e julgamento estético, e epistêmico (os juízos de atribuição e de existência freudianos), são suficientemente importantes para pensarmos que os argumentos acima precisam urgentemente ser atualizados. Isso implica, como buscamos demonstrar, modificações significativas nas formas de a psicanálise considerar a afirmação sexuada.

Para concluir, provisoriamente, gostaríamos de retomar a questão inicial da virtualidade do corpo na obra de arte, e a noção ambígua, muito utilizada pela crítica cultural, de "simulacro". O simulacro é, como sabemos, aquele que "não é" o verdadeiro, mas que assume seu lugar. Sua função na contemporaneidade, ou pós-modernidade, contém uma medida de engano diferente da simples representação. Ao invés de substituir simbolicamente a realidade, o simulacro se apresenta como tal: toma seu lugar e estatuto, valendo-se de seus próprios elementos. Conforme Jeudy (2002), a produção do simulacro coloca em causa um tipo de imitação que, de tão completa, "nega a si mesma": Assim, "o simulacro - escreve ele - não simula mais nada, torna-se o corpo em si” (p. 32).

Um exemplo dessa questão, na ordem sexual, é o travestismo. O jogo do é/ não é na sexuação faz valer aí toda sua ambiguidade em relação ao referente. Em um texto chamado "escritura/travestimento", Severo Sarduy (1975) propõe uma leitura interessante a esse respeito. Ele toma para análise o livro "El lugar sin limites", de José Donoso (1966), situando sua posição de "continuidade da tradição mítica do 'mundo ao contrário' que praticaram os surrealistas" (p. 46). Nesse romance do autor chileno, a personagem Manuela é um travesti que atrai uma mulher, a Japonesa. Conforme Sarduy, ela/ele (o travesti) se significa como mulher, mas "funciona" como homem.

$\mathrm{O}$ enredo introduz, nesse ponto, o que ele denomina de uma "primeira inversão", no interior da qual surge uma outra. Sobre ela, escreve o autor: "no ato sexual o papel de Manuela, homem por atribuição narrativa, é passivo. (...) A Japonesa o possui, fazendo-se possuir por ele" (p. 46). Tal estratégia narrativa é denominada por Sarduy de "Metáfora da boneca russa", indicando a continuidade que há entre espaço narrativo e as paixões que são retratadas no enredo. O argumento do romance é, nesse sentido, uma reflexão do próprio ato de construção narrativa. Metalinguagem (como denomina a crítica literária) e que desnuda, como na produção onírica (p. 47), o ponto de enlace entre sexuação e representação no simulacro literário.

Porém, a lógica da virtualidade do simulacro aí se inverte: "o que nos engana - escreve Sarduy - é o que constitui a suposta exterioridade da literatura" 
(p. 48). Preconceito atribuído à suposição "realista" da existência de uma realidade exterior ao texto, que o autor se limitaria a expressar e a traduzir.

O travestismo é, pois, nesse livro de Donoso a própria metáfora do que é o trabalho de escrita. Poderíamos ampliar esse princípio para a produção de qualquer tipo de ficção: das artes plásticas à construção singular de uma posição sexuada.

Segundo as palavras de Sarduy (1975):

O travestimento, tal e qual o pratica o romance de Donoso, seria a melhor metáfora do que é a escritura: o que Manuela nos faz ver não é uma mulher sob a aparência da qual se esconderia um homem, uma máscara cosmética que ao cair revelasse uma barba, um rosto maltratado e duro, mas o próprio fato do travestimento. (...) Sobrancelhas pintadas e barba: essa máscara mascara que é máscara: essa é a realidade (sem limites, já que tudo é contaminado por ela) que o herói de Donoso enuncia. Esses planos de intersexualidade são análogos aos planos de intertextualidade que constituem o objeto literário. (...) essa paródia é a escritura. (p. 49-50)

"Escritura/travestimento": outro modo de enunciar o enlace entre representação e sexuação. Partilhando do mesmo princípio - sendo ambos alegoria, um do outro - denotam a necessidade constante de a pesquisa psicanalítica se dedicar (e se atualizar) ao estudo do campo da arte e das produções culturais.

\section{Referências}

Donoso, J. El lugar sin límites. 5. ed. Santiago de Chile: Aguilar Chilena, 1995.

Foucault, M. Isto não é um cachimbo. Rio de Janeiro: Paz e Terra, 1988.

. As palavras e as coisas: uma arqueologia das ciências humanas. São Paulo: Martins Fontes, 1990.

. Arqueologia das ciências e história dos sistemas de pensamento. In: Ditos \& escritos. Rio de Janeiro: Forense Universitária, 2005. v. II.

Freud, S. (1900). La interpretación de los sueños. In: Obras Completas. Madrid: Biblioteca Nueva, 1973. tomo I.

. (1910). Un recuerdo infantil de Leonardo da Vinci. In: Obras Completas. Madrid: Biblioteca Nueva, 1973. tomo II.

. (1925a). La negacion. In: Obras Completas. Madrid: Biblioteca Nueva, 1973. tomo III.

. (1925b). Algunas consecuencias psiquicas de la diferencia sexual anatômica. In: Obras Completas. Madrid: Biblioteca Nueva, 1973. tomo III. 


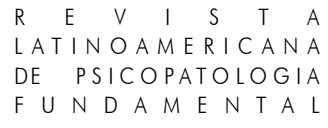

(1927). Fetichismo. In: Obras Completas. Madrid: Biblioteca Nueva, 1973.

Jeudy, H. O corpo como objeto de arte. São Paulo: Estação Liberdade, 2002.

Lacan, J. (1958-1959). O seminário. Livro 6. O desejo e sua interpretação. Inédito. . O seminário. Livro 20. Mais, ainda. Rio de Janeiro: Jorge Zahar, 1985. O seminário. Livro 7. A ética da psicanálise. Rio de Janeiro: Jorge Zahar, 1988.

Polı, M. C. Feminino/Masculino: a diferença sexual em psicanálise. Rio de Janeiro: Jorge Zahar, 2007.

SARduY, S. (1975). Escrito sobre um corpo. São Paulo: Perspectiva, 1979.

WILDE, O. O retrato de Dorian Gray. Rio de Janeiro: Civilização Brasileira, 1998.

\section{Resumos}

(Sexuación y formas de representación en la contemporaneidad)

Este trabajo se propone abordar el enlace entre lo singular del sujeto sexuado y los modos de representación, culturales por principio. Hemos seguido los pasos de Foucault que en su debate con Magritte, contextualiza las vicisitudes de la representación permitiendo abordar, desde la perspectiva del psicoanálisis, su relación con la sexuación. La filosofía, el arte y el psicoanálisis son prácticas distintas, sin embargo, inmersas en la misma cultura, necesitando hacer una actualización de sus relaciones.

Palabras claves: Cuerpo, arte, psicoanálisis, Lacan, Freud, Foucault

(La sexuation et les modes contemporains de représentation)

Cet article analyse le lien entre le singulier du sujet sexué et les modes de représentation qui sont par principe culturels. Nous prenons appui sur le travail de Foucault qui, dans son débat avec Magritte, situe les vicissitudes de la représentation, ce qui nous permet d'approcher son rapport avec la sexuation à partir de la psychanalyse. La philosophie, l'art et la psychanalyse sont des pratiques différentes, mais qui font partie du même milieu culturel, ce qui exige qu'on mette leurs débats à jour.

Mots clés: Corps, art, psychanalyse, Lacan, Freud, Foucault

(Sexuation and contemporary forms of representation)

This article discusses the relationships between the individual nature of sexuation and modes of its representations in culture. The approach presented by Foucault in his 
debate with Magritte is discussed. Foucault refers to the ways and byways taken by representation, discusses its relationships with psychoanalysis, and links them with sexuation. Philosophy, art and psychoanalysis are different praxes but they are all present in the same cultural melting pot. Therefore, the debate on them should be taken seriously.

Key words: Body, art, psychoanalysis, Lacan, Freud, Foucault

Citação/Citation: Pol, M. C. Sexuação e formas contemporâneas de representação. Revista Latinoamericana de Psicopatologia Fundamental, São Paulo, v. 12, n. 2, p. 303-315, jun. 2009.

Editor do artigo/Editor: Prof. Dr. Manoel Tosta Berlinck.

Recebido/Received: 3.4.2008 / 4.3.2008 Aceito/Accepted: 28.5.2008 / 5.28.2008

Copyright: () 2009 Associação Universitária de Pesquisa em Psicopatologia Fundamental/ University Association for Research in Fundamental Psychopathology. Este é um artigo de livre acesso, que permite uso irrestrito, distribuição e reprodução em qualquer meio, desde que $\mathrm{o}$ autor e a fonte sejam citados/This is an open-access article, which permits unrestricted use, distribution, and reproduction in any medium, provided the original author and source are credited.

Financiamento/Funding: Esta pesquisa foi financiada pelo Conselho Nacional de Desenvolvimento Científico e Tecnológico - CNPq/This research has been funded by the National Counsel of Technological and Scientific Development.

Conflito de interesses: $\mathrm{O}$ autor declara que não há conflito de interesses/The author declares that has no conflict of interest.

\section{Maria Cristina Poli}

Psicanalista; membro da Associação Psicanalítica de Porto Alegre - APPOA (Porto Alegre, RS, Brasil); doutora em Psicologia pela Université Paris -13 e pós-doutora no programa de pós-graduação em Teoria Psicanalítica da Universidade Federal do Rio de Janeiro - UFRJ (Rio de Janeiro, RJ, Brasil); professora do Programa de Pós-graduação em Psicologia Social e Institucional da Universidade Federal do Rio Grande do Sul - UFRGS (Porto Alegre, RS, Brasil); coordenadora, junto com Edson de Sousa, do LAPPAP - Laboratório de Pesquisa em Psicanálise, Arte e Política (Porto Alegre, RS, Brasil); pesquisadora do Conselho Nacional de Desenvolvimento Científico e Tecnológico - CNPq.

Rua Augusto Pestana, 146/302 90040-200 Porto Alegre, RS, Brasil

e-mail: crispoli@plugin.com.br 